\title{
Enhancement of cancer invasion and growth via the C5a-C5a receptor system: Implications for cancer promotion by autoimmune diseases and association with cervical cancer invasion
}

\author{
MASAKAZU YONEDA ${ }^{1,2}$, RYUJI IMAMURA ${ }^{1,3}$, HIDETOSHI NITTA $^{4}$, \\ KEISUKE TANIGUCHI ${ }^{5}$, FUMITAKA SAITO ${ }^{6}$, KEN KIKUCHI $^{7}$, HIDENAO OGI $^{2}$, TAKUYA TANAKA ${ }^{2}$, \\ HIDETAKA KATABUCHI $^{6}$, HIDEKI NAKAYAMA ${ }^{2}$ and TAKAHISA IMAMURA ${ }^{1}$
}

\begin{abstract}
Departments of ${ }^{1}$ Molecular Pathology, ${ }^{2}$ Oral and Maxillofacial Surgery, ${ }^{3}$ Urology and ${ }^{4}$ Gastroenterological Surgery, Faculty of Life Sciences, Kumamoto University, Kumamoto 860-8556, ${ }^{5}$ Pharmaceutical Research Department, Yakult Central Institute for Microbiological Research, Tokyo 186-8650, ${ }^{6}$ Department of Obstetrics and Gynecology, Faculty of Life Sciences, Kumamoto University, Kumamoto 860-8556;

${ }^{7}$ Operations Division, Sakurajyuji Hospital, Kumamoto 861-4173, Japan
\end{abstract}

Received May 12, 2018; Accepted October 26, 2018

DOI: $10.3892 / \mathrm{ol} .2018 .9715$

\begin{abstract}
Autoimmune diseases are caused by immune complex-induced activation of the complement system and subsequent inflammation. Recent studies have revealed an association between autoimmune diseases and worse survival in patients with cancer; however, the underlying mechanism is still unknown. The C5a-C5a receptor (C5aR) system has been shown to enhance cancer activity and recruit myeloid-derived suppressor cells (MDSCs) that suppress the anti-tumor immune response. The Arthus reaction is inflammation caused by complement system activation by the immune complex and thus is a model of autoimmune diseases. To explore the effect of the Arthus reaction on cancer progression, mouse cancer cells were inoculated in syngeneic mouse skin, where the Arthus reaction was induced simultaneously. The Arthus reaction enhanced invasion and tumor growth of C5aR-positive cancer cells, but not control cells, and induced MDSC recruitment. Intravenous injection of C5a-stimulated C5aR-positive cancer cells into nude mice resulted in more lung nodules than injection of nontreated C5aR-positive cells and C5a-stimulated C5aR-negative cells, supporting C5a-C5aR-mediated enhancement of cancer growth. C5aR expression in uterine cervical carcinoma stage I cells, which invade into the deeper tissues,
\end{abstract}

Correspondence to: Dr Takahisa Imamura, Department of Molecular Pathology, Faculty of Life Sciences, Kumamoto University, 1-1-1 Honjo, Kumamoto 860-8556, Japan

E-mail: taka@kumamoto-u.ac.jp

Abbreviations: C5aR, C5a receptor; CIN, cervical intraepithelial neoplasia; MDSC, myeloid-derived suppressor cell

Key words: anaphylatoxin C5a, CD88, autoimmune, Arthus, invasion, growth, metastasis, cervical cancer was significantly higher than that in CIN3 cells, which remain in the epithelium. These results indicate that cancer promotion by the C5a-C5aR system may underlie poor prognosis in cancer patients with autoimmune diseases, particularly in patients with C5aR-positive cancer, and may be associated with cervical cancer invasion. The enhancement of cancer cell invasion and growth by the C5a-C5aR system suggests that this system is a possible target of cancer therapy.

\section{Introduction}

Autoimmune diseases are caused by immune complex-induced activation of the complement system and subsequent inflammation, both of which injure tissues (1). Recent studies have revealed an association between autoimmune diseases, including rheumatoid arthritis and thyroiditis, and worse survival in patients with lung, breast, or thyroid cancers (2-4); however, the underlying mechanism is still unclear.

Anaphylatoxin C5a, an N-terminal 74-amino acid fragment of the $\alpha$-chain of the complement fifth component (C5) (5), is a byproduct of complement activation and functions as a leukocyte chemoattractant and inflammatory mediator $(6,7)$. There is emerging evidence supporting a role for $\mathrm{C} 5 \mathrm{a}$ in cancer. C5a recruits myeloid-derived suppressor cells (MDSCs) that inhibit the $\mathrm{CD}^{+}$cytotoxic $\mathrm{T}$ cell-mediated anti-tumor response (8), facilitating increased survival of cancer cells. C5a induces endothelial cell chemotaxis and blood vessel formation (9), thereby promoting neovascularization (10). Thus, C5a indirectly aids cancer development and progression by creating a microenvironment favorable for cancer cells. C5a acts by binding to the C5a receptor (C5aR; CD88) on the cell membrane (11). We previously showed that a variety of cancer cells aberrantly express $\mathrm{C} 5 \mathrm{aR}$ at varying rates in organs, and that C5a enhances cancer cell mobility, matrix metalloprotease (MMP) secretion, and invasiveness in vitro and in nude mouse skin via C5aR (12). Thus, the C5a-C5aR system was suggested to be directly involved in cancer progression. Activation of the 
complement system has been shown to occur in cancer tissues in human specimens $(13,14)$ and animal models $(8,9)$, indicating generation of C5a in the cancer microenvironment. Moreover, human cancer cells release C5a from human C5 and plasma via a serine protease on the cell membrane (15). The survival rates of patients with C5aR-positive or highly expressing non-small cell lung (16), breast (17), urothelial (18), clear cell renal (19), and gastric cancers $(20,21)$ are lower than those of patients with the corresponding C5aR-negative cancers. It is likely that the C5a-C5aR system promotes human cancer. C5a enhances cancer cell activities in a concentration-dependent manner (12) and the plasma C5a level was elevated in patients with autoimmune diseases, such as systemic lupus erythematosus (22) or rheumatoid arthritis (23). Accordingly, cancer promotion by the C5a-C5aR system may be exaggerated in autoimmune diseases.

The Arthus reaction is a model of autoimmune diseases and caused by immune complex-triggered complement activation $(24,25)$. To explore the mechanism underlying the poor prognosis of cancer patients with autoimmune diseases (2-4), the effect of the Arthus reaction on cancer invasion and growth, and MDSC recruitment was investigated using wild-type mice and syngeneic cancer cells with or without C5aR expression. The C5a-C5aR system was further examined in lung nodules formed by cancer cells intravenously injected into mice and in uterine cervical cancer invasion using clinically obtained tissue samples of the cancer.

\section{Materials and methods}

Materials and animals. Recombinant human C5a and anti-human C5aR mouse monoclonal $\mathrm{IgG}$ were purchased from EMD Millipore (Billerica, MA, USA) and Hycult Biotech (Uden, The Netherlands), respectively. A set of anti-Ki-67 antibody and EnVision ${ }^{+}$solution was purchased from Dako; Agilent Technologies, Inc., (Santa Clara, CA, USA). Polyclonal anti-ovalbumin mouse IgG and anti-BSA mouse IgG were purchased from Condrex (Redmond, WA, USA) and Rockland (Limerick, PA, USA), respectively. Ovalbumin and bovine serum albumin (BSA) were obtained from Sigma-Aldrich; Merck KGaA, (Darmstadt, Germany). Anti-mouse Ly6g rat IgG labeled with $\mathrm{Cy}-5^{\circledR}$ and anti-mouse $\mathrm{CD} 11 \mathrm{~b}$ rat IgG labeled with fluorescein isothiocyanate (FITC) were from Abcam (Cambridge, UK). The near-infrared ray cell labeling probes Qtracker 655 and Qtracker 800 were from Thermo Fisher Scientific, Inc., (Waltham, MA, USA). Other chemicals were purchased from Wako Pure Chemical Industries (Osaka, Japan). Nude mice and Balb/c mice were supplied by Kyudo Experimental Animal Corp., (Kumamoto, Japan). The animal experiments were approved by the Kumamoto University Animal Experiment Committee (A 29-29) and performed according to the criteria of the Committee.

Cells. The human bile duct cancer cell line HuCCT1 was provided by the Cell Resource Center for Biomedical Research Institute of Development, Aging, and Cancer, Tohoku University (Sendai, Japan). The mouse kidney cancer cell line Renca (CRL-2947) was obtained from the American Type Culture Collection. The cells were cultured in RPMI 1640 medium supplemented with $10 \%$ fetal bovine serum (FBS), penicillin $(40 \mathrm{U} / \mathrm{ml})$, and streptomycin $(40 \mu \mathrm{g} / \mathrm{ml})$ and maintained at $37^{\circ} \mathrm{C}$ in $5 \% \mathrm{CO}_{2}$. HuCCT1 and Renca cells do not express $\mathrm{C} 5 \mathrm{aR}$, but we established HuCCT1 cells stably expressing C5aR (HuCCT1/C5aR) by transfection with a plasmid carrying human C5aR cDNA (12) and Renca cells stably expressing C5aR (Renca/C5aR) by transfection with a plasmid carrying mouse C5aR cDNA (26).

Invasion assay. Mouse cancer cells expressing C5aR and the control cells from the same mother cells were necessary in the invasion assay. Thus, previously established Renca/C5aR cells and Renca/mock cells (26) were used. Renca/C5aR cells and Renca/mock cells were incubated in $10 \mathrm{nM}$ Qtracker 800 and Qtracker 655, respectively, at a density of $1 \times 10^{7}$ cells $/ \mathrm{ml}$ in PBS at $37^{\circ} \mathrm{C}$ for $1 \mathrm{~h}$. The cells were washed with PBS and suspended in PBS at $2 \times 10^{7}$ cells $/ \mathrm{ml}$. Equal volumes of the Renca/C5aR and Renca/mock cell suspensions were mixed. To induce the passive Arthus reaction, $10 \mu \mathrm{l}$ of anti-ovalbumin or control mouse IgG (10 mg/ml PBS) was added to $40 \mu \mathrm{l}$ of the cell mixture, and the mixture was injected intradermally into depilated Balb/c mice sedated by an intraperitoneal (i.p.) injection of ketamine (140 mg/kg body weight), followed by injection of $200 \mu \mathrm{l}$ of ovalbumin $(10 \mathrm{mg} / \mathrm{ml})$ via the tail vein. After 24 or $48 \mathrm{~h}$, the mice were sacrificed by cervical dislocation and cancer cell-injected skin tissues were harvested, fixed in formalin and embedded in paraffin. Fluorescence from the cells labeled with near-infrared ray probes in $4-\mu \mathrm{m}$-thick tissue sections was measured using a BZ-X710 fluorescence microscope (Keyence Corporation, Osaka, Japan). Qtracker 800 and Qtracker 655 were observed at $810 \mathrm{~nm}$ emission with $710 \mathrm{~nm}$ excitation and $630 \mathrm{~nm}$ emission with $560 \mathrm{~nm}$ excitation and colored in green and red, respectively. To quantify the distribution of cancer cells, the areas with fluorescent dots representing labeled cells were encircled, and the area size was measured using imaging analysis software (VH-Analyzer; Keyence Corporation). The ratio of the distribution areas of Renca/C5aR cells to those of Renca/mock cells was calculated.

Assessment of tumor growth and myeloid-derived suppressor cell (MDSC) accumulation. Cell suspension (50 $\mu 1,2 \times 10^{6}$ cells) supplemented with anti-BSA or control mouse $\operatorname{IgG}(25 \mu \mathrm{g})$ was injected intradermally into depilated Balb/c mice sedated by an i.p. injection of ketamine (140 $\mathrm{mg} / \mathrm{kg}$ body weight), followed by injection of $200 \mu \mathrm{l}$ of BSA $(10 \mathrm{mg} / \mathrm{ml})$ via the tail vein. The tumor size was calculated by multiplying the lengths of the major and minor axes. After 14 days, the mice were sacrificed by cervical dislocation, tumors were harvested, and the $4-\mu \mathrm{m}$-thick frozen sections were prepared and immunostained with anti-mouse Ly6g rat IgG labeled with PE/Cy-5 ${ }^{\circledR}$ (1:100 dilution) and anti-mouse CD11b rat $\operatorname{IgG}$ labeled with FITC (1:100 dilution). Fluorescence was observed with a fluorescence microscope (BZ-X710) at 590-650 nm excitation and 662.5-737.5 $\mathrm{nm}$ emission for PE/Cy-5 ${ }^{\circledR}$ and at $450-490 \mathrm{~nm}$ excitation and 500-550 nm emission for FITC. Double-positive cells, recognized as MDSCs (27), were counted in five randomly selected high-power fields (x400), and the average cell number per high-power field was determined.

Assessment of nodule formation in the lungs. Cancer cells expressing C5aR and control cells from the same mother 
cells were used to assess lung nodule formation. As bile duct cancer has the highest in C5aR-positive rate among human cancers (12), it was suggested to be most affected by the C5a-C5aR system. In a previous study, we established HuCCT1/C5aR cells and HuCCT1/mock cells for the previous study and demonstrated enhancement of HuCCT1/C5aR cell invasion by C5a in the nude mouse skin (12). In connection with this study, we used the same two HuCCT1 bile duct cancer cell lines. HuCCT1/C5aR and HuCCT1/mock cells were incubated in RPMI 1640 medium in the presence or absence of $100 \mathrm{nM}$ C5a for $6 \mathrm{~h}$. After washing with PBS, cells were suspended in PBS $\left(1 \times 10^{7}\right.$ cells $\left./ \mathrm{ml}\right)$ and $0.1 \mathrm{ml}$ of the suspension was injected into nude mice via the tail vein. Six weeks later, the mice were sacrificed by cervical dislocation and the lungs were harvested, fixed in formalin and embedded in paraffin. Sections of 3- $\mu \mathrm{m}$ thickness were prepared from the paraffin-embedded lungs for hematoxylin-eosin staining. For Ki-67 immunohistochemical staining, the deparaffinized lung sections were autoclaved for $15 \mathrm{~min}$ in $10 \mathrm{mM}$ citrate buffer, $\mathrm{pH}$ 6.0. The sections were washed with PBS, incubated with anti-Ki-67 antibody (1:50 dilution) at room temperature for $1 \mathrm{~h}$, and stained using EnVision $^{+}$solution and 3,30-diaminobenzidine tetrahydrochloride solution containing $0.006 \% \mathrm{H}_{2} \mathrm{O}_{2}$, according to the manufacturer's instructions. Nuclei were counterstained with hematoxylin. To evaluate nodule formation, nodules containing Ki-67-positive cells were counted in five random microscopic fields (x100) in a section, and the total number of nodules was determined.

C5aR immunohistochemistry. Uterine cervical tissue biopsy samples obtained from the Kumamoto University Hospital from January to December 2015 and diagnosed as cervical intraepithelial neoplasia (CIN3) or squamous cell carcinoma stage I according to the FIGO staging system 2008 (28) were examined for C5aR expression. Written informed consent for the tissue usage was obtained from the patients, and the use of these tissues was approved by the internal ethics committee (Rinri No. 706).

Cervical squamous cell carcinoma stage I differs from CIN 3 in terms of tumor cells invasion from the epithelium; thus, C5aR expression between the two stages may be compared to explore possible involvement of the C5a-C5aR system in human cancer invasion. Deparaffinized 3- $\mu \mathrm{m}$-thick sections were pretreated with $0.3 \% \mathrm{H}_{2} \mathrm{O}_{2}$ in methanol for $20 \mathrm{~min}$, followed by Protein Block, Serum-Free (Dako Cytomation, Glostrup, Denmark) treatment for $20 \mathrm{~min}$. The sections were incubated with anti-human C5aR mouse monoclonal IgG $(2 \mu \mathrm{g} / \mathrm{ml})$ at room temperature for $1 \mathrm{~h}$ and subsequently stained using EnVision ${ }^{+}$solution and 3,30-diaminobenzidine tetrahydrochloride solution containing $0.006 \% \mathrm{H}_{2} \mathrm{O}_{2}$, according to the manufacturer's instructions. Nuclei were counterstained with hematoxylin. Normal mouse IgG was used rather than the primary antibody as a negative control, and it did not react with the tissue sections. For each section, high or low C5aR expression was defined as C5aR-positive cancer cell area $>30 \%$ or $0-30 \%$ of the total cancer cell area, respectively, according to previous methods $(29,30)$.

Statistical analyses. Experimental data were expressed as average \pm SD. Groups were compared using the Stata statistical software, release 15.1 (Stata Corp LP, College Station, TX, USA) by analysis of variance (ANOVA) Wilcoxon rank-sum (Mann-Whitney) test for nonparameric distribution followed by Bonferroni multiple-comparison adjustment or Student's t-test for normal distribution. The association of C5aR expression with invasion in uterine cervical cancer was analyzed using Fisher's exact test. $\mathrm{P}<0.05$ was considered to indicate a statistically significant difference.

\section{Results}

Arthus reaction enhances the invasion and growth of C5aR-positive cancer cells and induces MDSC recruitment. To determine whether autoimmune reactions affect cancer progression, the Arthus reaction was induced in the Renca cell-injected wild-type mouse skin site using the mouse immune-complex, and the effect of the reaction on the spread of the cells was studied. To avoid the immune response against Renca cells, which were derived from a Balb/c mouse (31), Balb/c mice were used. To exclude differences in experimental conditions (injection volume and site and Arthus reaction intensity) between Renca/C5aR and Renca/mock cells, the Renca-derived cells were mixed and injected into the mouse skin with the mouse antibody, followed by intravenous injection of the antigen. In the presence of the Arthus reaction, Renca/C5aR cells spread to a larger area than Renca/mock cells did; however, in the absence of the reaction, the distribution areas of the two types of cells were not different (Fig. 1A). At $24 \mathrm{~h}$ after the initiation of the reaction, the distribution area of Renca/C5aR cells was $\sim 1.3$-fold larger than that of Renca/mock cells (Fig. 1B). The C5aR-dependent enhancement of Renca cell invasion indicated that endogenous C5a contributed to the enhanced cancer invasion induced by the Arthus reaction. Next, we examined whether the Arthus reaction enhanced the tumor growth of Renca cells inoculated in the wild-type mouse skin. In the presence of the Arthus reaction, the tumor size of Renca/C5aR cells increased by approximately 1.4-fold at day 7 and 1.6-fold at day 14, but the reaction did not affect the growth of tumors formed by Renca/mock cells (Fig. 1C and D). MDSCs suppress the $\mathrm{CD} 8^{+} \mathrm{T}$ cell-mediated anti-tumor response (8), thus facilitating tumor growth. Hence, the effect of the Arthus reaction on the accumulation of MDSCs in Renca cell-injected sites was analyzed. A considerable number of MDSCs (cells with yellow fluorescence in merged images) was present in the skin sites after the Arthus reaction, but few MDSCs were seen in the cancer tissue without the reaction (Fig. 1E). The number of recruited MDSCs was significantly increased by the Arthus reaction in the cancer cell injection sites (Fig. 1F); however, no significant difference in MDSC number between the sites injected with Renca/C5aR or Renca/mock cells was observed (Fig. 1F). Thus, it is likely that the enhanced tumor growth of Renca/C5aR cells by the Arthus reaction (Fig. 1D) was caused by the C5a-C5aR system rather than antitumor immune response suppression by MDSCs.

C5 a promotes nodule formation of C5aR-positive cancer cells in the lungs. C5a does not affect the anoikis of cancer cells (26), but the positive correlation of patients' cancer cell C5aR expression 


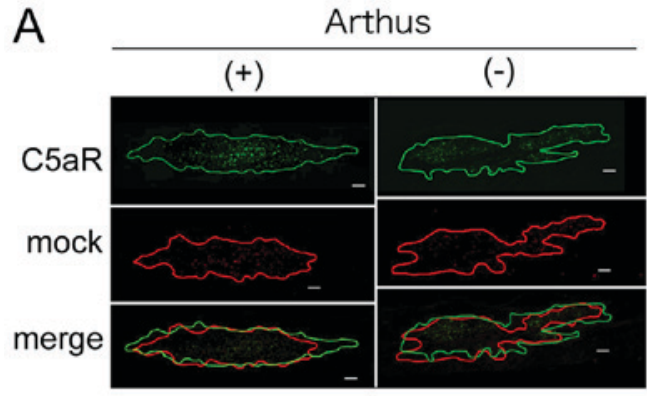

C

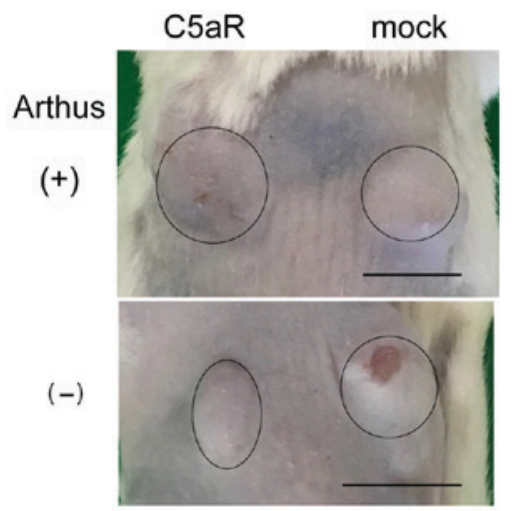

E

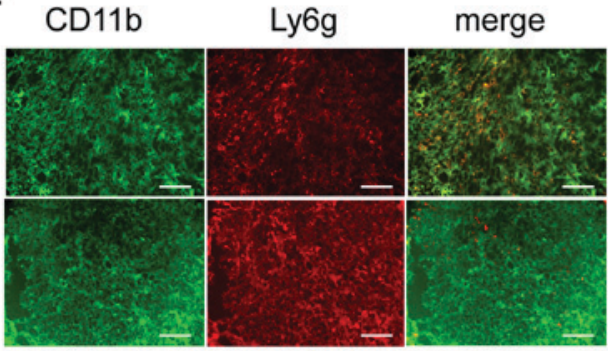

B

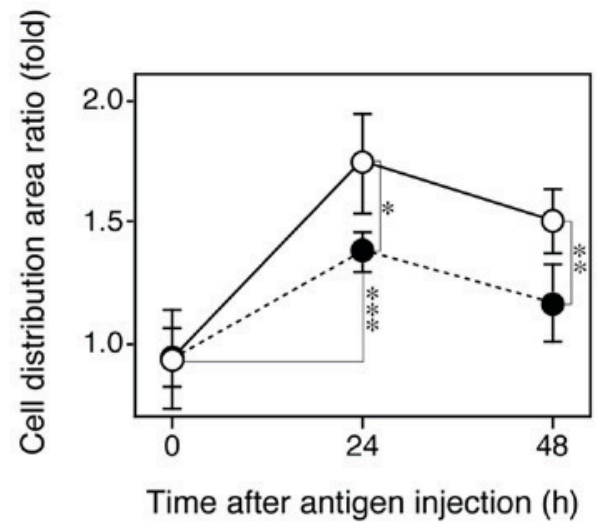

D

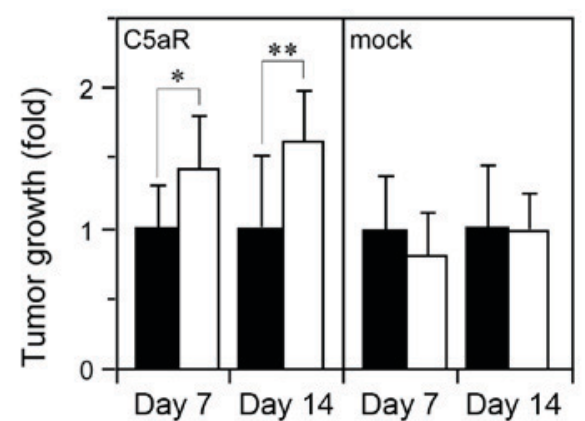

F

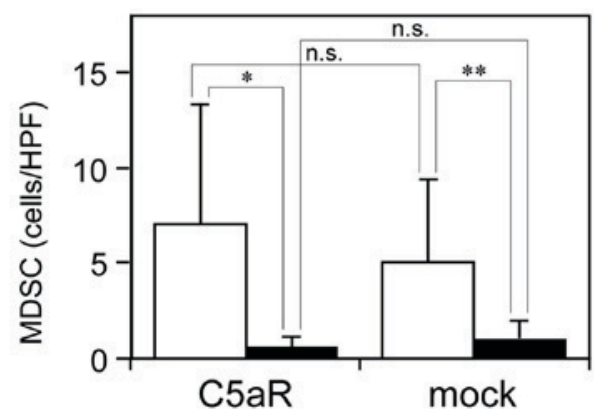

Figure 1. Promotion of C5aR-positive cancer cell invasion, tumor growth, and induction of MDSC recruitment by the Arthus reaction. Renca/C5aR cells (green) and Renca/mock cells (red) were labeled with different fluorescence probes, mixed, and injected subcutaneously into a wild-type mouse in combination with anti-ovalbumin mouse IgG or control IgG, followed by intravenous injection of ovalbumin (A, B) or with anti-BSA mouse IgG or control IgG, followed by intravenous injection of BSA (C-F). (A) Skin areas showing fluorescence from Renca/C5aR cells and Renca/mock cells (encircled in green and red lines, respectively), $24 \mathrm{~h}$ after ovalbumin injection. Scale bar: $200 \mu \mathrm{m}$. (B) Ratio of fluorescence distribution area of Renca/C5aR cells vs. that of Renca/mock cells was calculated. The values indicate the mean \pm SD $(n=4)$. Open circles: Anti-ovalbumin IgG; closed circles: Control IgG. Values were compared by analysis of variance (ANOVA) followed by Bonferroni multiple-comparison adjustment. ${ }^{*} \mathrm{P}=0.03$, ${ }^{* *} \mathrm{P}=0.067,{ }^{* * *} \mathrm{P}=0.008$. $(\mathrm{C})$ Images showing tumors at Renca cell-injected sites in the presence or absence of the Arthus reaction at day 14. Tumors are encircled in black lines. Scale bar: 1 cm. (D) Tumor growth at 7 and 14 days in sites subcutaneously injected with anti-BSA IgG (open column) or control IgG (closed column) after an intravenous BSA injection. Tumor size was measured and expressed as a ratio relative to the average tumor size in the absence of the Arthus reaction and vertical bars indicate the SD $(\mathrm{n}=6) .{ }^{*} \mathrm{P}=0.036,{ }^{* *} \mathrm{P}=0.021$. (E) Fluorescence immunohistochemistry of Renca/C5aR cell-injected sites at day 14 using FITC-labeled anti-mouse CD11b rat $\mathrm{IgG}$ and $\mathrm{Cy}-5^{\circledR}$-labeled anti-mouse Ly6g rat IgG. Upper and lower panels are from the sites where the Arthus reaction was induced or not, respectively. Scale bar: $50 \mu \mathrm{m}$. (F) MDSCs (CD11b+Ly6g $\mathrm{g}^{+}$were counted in the cancer tissues where the Arthus reaction was induced (open column) or not (closed column) and the average MDSCs/high-power field $(\mathrm{HPF}) \pm \mathrm{SD}(\mathrm{n}=6)$ were recorded. Values were compared by Wilcoxon rank-sum (Mann-Whitney) test for nonparameric distribution followed by Bonferroni multiple-comparison adjustment. ${ }^{*} \mathrm{P}=0.031,{ }^{* *} \mathrm{P}=0.031, \mathrm{n} . \mathrm{s}$, not significant.

with vascular invasion in the primary sites $(20,21,26)$ and with metastasis $(16,17,26)$ suggested the involvement of C5a in the entry of cancer cells into the circulation through the endothelial layer and subsequent cancer growth in metastasized organs. To further investigate the effect of the C5a-C5aR system on cancer tumor growth, cancer cells were injected intravenously into nude mice, and to evaluate tumor growth cancer cell nodule formation in the lungs was examined. The lungs appeared to be unchanged and no cancer cell nodules were visible macroscopically. However, micro-nodules were observed in the lungs microscopically (Fig. 2A). As these nodules contained Ki-67-positive cells, they were recognized as cancer cell nodules (Fig. 2B). Nodules formed by C5a-stimulated C5aR-positive cancer cells appeared larger, and the number of nodules was approximately three-fold higher than that formed by non-stimulated C5aR-positive cancer cells, which showed a nodule number almost equal to 

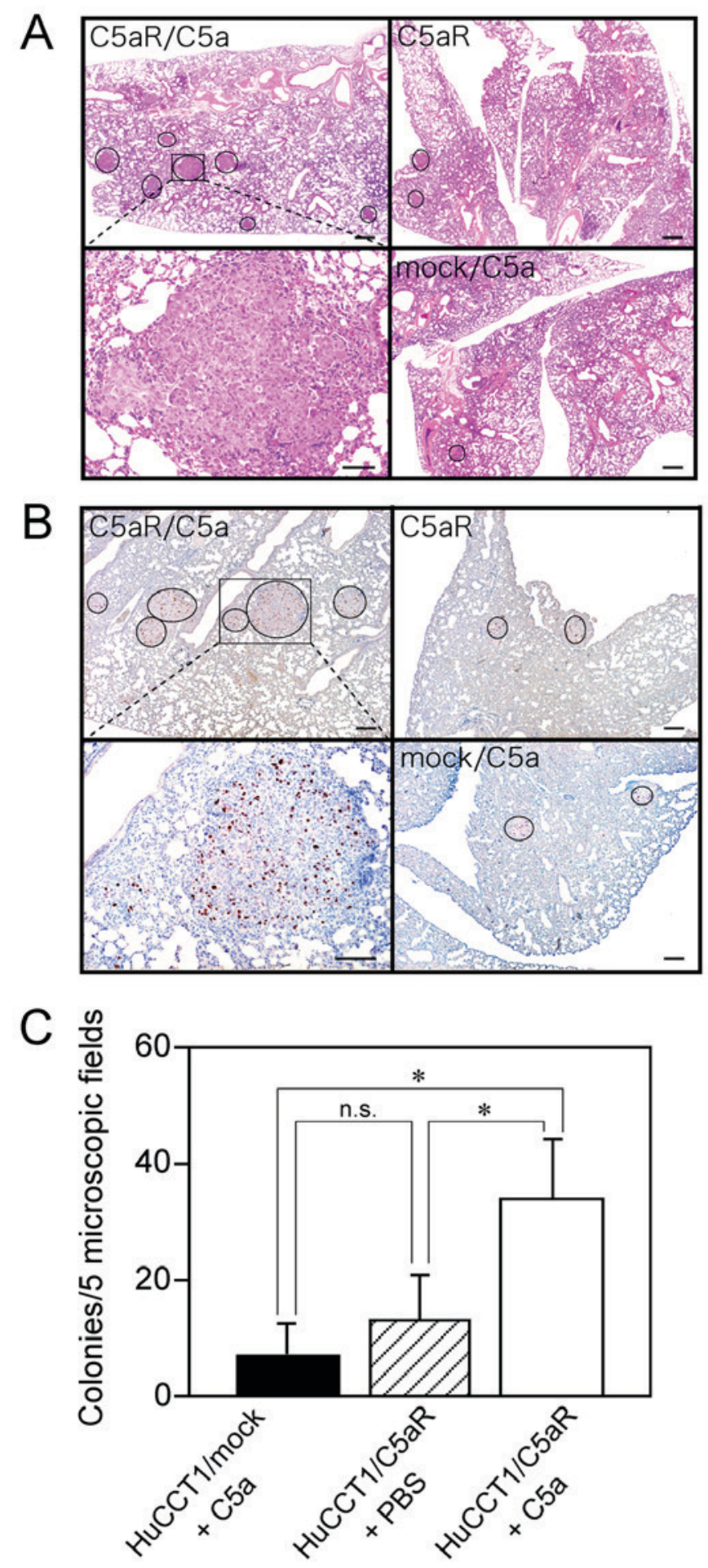

Figure 2. Increase in lung nodules of C5aR-positive cancer cells stimulated with C5a and injected intravenously. (A) HuCCT1/C5aR cells incubated in the presence or absence of $\mathrm{C} 5 \mathrm{a}$ or $\mathrm{HuCCT} 1 /$ mock cells incubated with $\mathrm{C} 5 \mathrm{a}$ in the lung tissues of nude mice 6 weeks after cancer cell injection (hematoxylin-eosin stain). Nodules are encircled. Scale bar: $200 \mu \mathrm{m}$. The area in the square in the upper left panel is magnified in the lower left panel. Scale bar: $50 \mu \mathrm{m}$. (B) Lung tissues of nude mice six weeks after injection with cancer cells (Ki-67 immunohistochemical stain). Cancer nodules containing $\mathrm{Ki}$-67-positive cells are encircled. HuCCT1/C5aR cells incubated in the presence (upper left) or absence (upper right) of C5a. HuCCT1/mock cells incubated with C5a (lower right). Scale bar: $200 \mu \mathrm{m}$. The area in the square in the upper left panel is magnified in the lower left panel. Scale bar: $200 \mu \mathrm{m}$. (C) Cancer nodules in five random microscopic fields (x100) in a section were counted, and the average colony number per field \pm SD was recorded $(n=6)$. ${ }^{*} \mathrm{P}<0.01$, n.s, not significant.

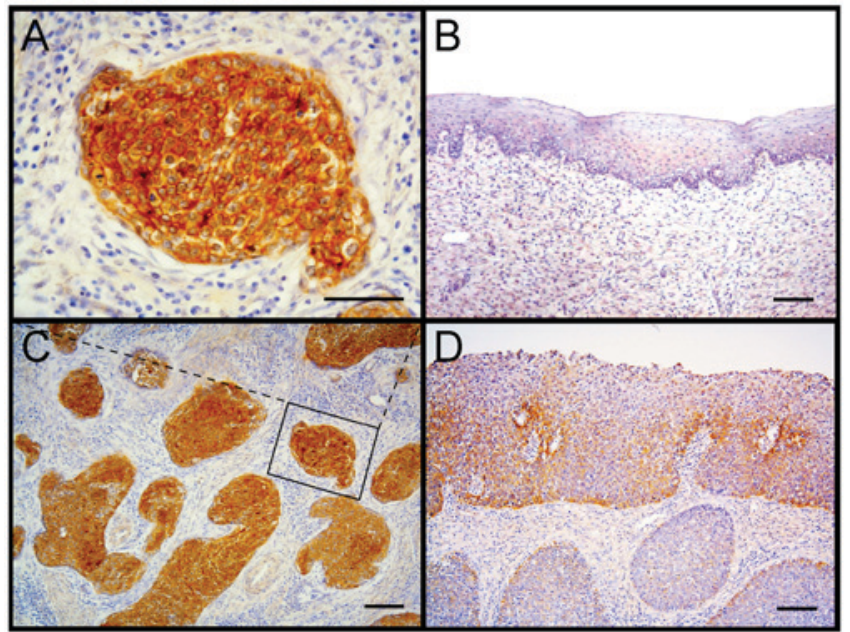

Figure 3. C5aR expression in uterine cervical cells. Uterine cervical tissue samples were immunostained using an anti-human C5aR antibody (A) Magnified image of the square marked in panel C. (B) Noncancerous epithelial cells. (C) Tissue with high C5aR expression. (D) Tissue with low C5aR expression. Scale bars: $50 \mu \mathrm{m}$ in A and $100 \mu \mathrm{m}$ in B-D.

that of C5a-stimulated C5aR-negative cancer cells (Fig. 2C). The enhanced lung nodule formation by cancer cells inoculated intravenously supported the tumor growth enhancement via the C5a-C5aR system (Fig. 1D) and suggested the possible participation of the system in the promotion of cancer metastasis.

High C5aR expression is associated with cervical cancer invasion in the uterus. In clinically obtained tissue samples, C5aR was expressed in urothelial carcinoma cells at the invasive front rather than the surface layer in the epithelium and in almost all the cells in the deeper invasion site (18), which, together with high C5aR expression in gastric cancer cells invading the adjacent blood vessels $(20,21)$, implies the involvement of the C5a-C5aR system in human cancer invasion. However, C5a-C5aR-mediated cancer invasion has not been fully elucidated in cancer patients. Cervical carcinoma cells at stage I invade into the deeper tissues of the uterus, whereas cells at CIN3 remain in the epithelium (19). To investigate the relationship between cancer cell C5aR expression and invasion in cancer patients, cervical tissue samples diagnosed as CIN3 or squamous cell carcinoma stage I were examined for C5aR expression of tumor cells (Fig. 3). Twenty-one of 49 samples tested were positive for C5aR (42.9\%) (95\% confidence interval: 29.0-56.8\%). C5aR was expressed on the cell membrane of the cancer cells (Fig. 3B). Noncancerous epithelial cells did not express C5aR (Fig. 3D). To evaluate the C5aR expression of cells at CIN3 or stage I, the tissue samples were further assessed for high $\mathrm{C} 5 \mathrm{aR}$ and low $\mathrm{C} 5 \mathrm{aR}$ expression (representative images in Fig. 3A and C, respectively). The proportion of cells with high C5aR expression was 38\% (10/23) in stage I cells and 12\% (3/26) in CIN3 cells, and it was significantly higher $(\mathrm{P}=0.021)$ at stage I than at CIN3 (Table I). The cells of the three CIN3 samples belonging to the high $\mathrm{C} 5 \mathrm{aR}$ expression group were all carcinoma in situ (CIS). The association of high C5aR expression with human cervical cancer invasion suggests that the C5a-C5aR system has an invasion-enhancing effect on cervical cancer. 
Table I. Association between C5a receptor expression and invasion in uterus cervical cancer.

\begin{tabular}{lcrr}
\hline & \multicolumn{2}{c}{ C5aR expression } & \\
\cline { 2 - 3 } Lesion & Low & High & P-value \\
\hline CIN3 & 23 & 3 & 0.021 \\
Stage I & 13 & 10 & \\
\hline
\end{tabular}

C5aR, C5a receptor; CIN3, cervical intraepithelial neoplasia 3.

\section{Discussion}

The Arthus reaction is caused by the immune complex-triggered complement activation $(24,25)$ and serves as a model of autoimmune diseases, in which excessive activation of the complement has been implicated $(1,32)$. Autoimmune-diseased organs and tissues have a high risk of cancer development $(33,34)$; hence, it is possible that the Arthus reaction occurs in cancer tissues. We showed that the Arthus reaction enhanced cancer invasion and growth in a C5aR-dependent manner and induced recruitment of MDSCs at the site (Fig. 1). Thus, the endogenous C5a in the reaction site acted on both cancer cells and the cancer microenvironment, synergistically promoting cancer. The cancer promotion by the Arthus reaction suggests that C5a generation may be an underlying mechanism for the poor prognosis of the cancer patients with autoimmune diseases (2-4), particularly patients with C5aR-positive cancers. The promotion of lung nodule formation of intravenously injected C5aR-positive cancer cells (Fig. 2) provides additional evidence of the tumor growth enhancement via the C5a-C5aR system. The significantly high proportion of cells with high C5aR expression at the early cervical cancer invasion stage in comparison with the non-invasive stage (Table I) clinically supports the association of the C5a-C5aR system with cancer invasion.

The C5aR-dependent enhancement of Renca cell invasion in the wild-type mouse skin (Fig. 1A and B) corresponded with the invasion-enhancing effect of recombinant mouse C5a on Renca/C5aR cells (26) and HuCCT1/C5aR cells in vitro and in nude mouse skin (12). However, contradictory results have been reported regarding the effect of $\mathrm{C} 5 \mathrm{a}$ on in vitro proliferation of cancer cells. C5a enhanced the proliferation of human breast $(17,35)$ and nasopharyngeal (36) cancer cells, but not that of mouse lung cancer cells (9), in a C5aR-dependent manner. In the current study, we found that the Arthus reaction augmented cancer cell growth in a C5aR-dependent fashion (Fig. 1D). The enhanced nodule formation of cancer cells in the mouse lung (Fig. 2C) indicated the growth-enhancing activity of C5a in C5aR-positive cancer cells. The C5aR-positive human cancer cells, once stimulated with C5a and washed, maintained their enhanced invasiveness (12); accordingly, C5a stimulation was presumably able to enhance the growth of C5aR-positive cancer cells in the lungs. The growth-enhancing activity of the C5a-C5aR system in Renca/C5aR cells in the Arthus reaction site (Fig. 1C and D) may have been increased by accumulated MDSCs (Fig. 1E and F), which suppress the anticancer immune response of $\mathrm{CD}^{+}$cytotoxic $\mathrm{T}$ cells and create a microenvironment favorable for cancer cells (8).

Examination of clinically obtained cancer tissue samples for cancer cell C5aR expression implicated the C5a-C5aR system in human cancer progression. Cancer cell C5aR expression correlated with advanced clinical stage $(17,20,21)$, presence of lymph node metastasis $(16,17)$, and low survival rate $(16,21)$. However, no clinical evidence has indicated a relationship between the C5a-C5aR system and cancer invasion. Cervical cancer cells at stage I invade to the deeper uterine tissues, whereas cells at CIN3 remain in the epithelial layer (28). Thus, cervical cancer cell invasion from the epithelial layer advances from CIN3 to stage I. A significantly higher proportion of cells with high C5aR expression at stage I compared to cells at CIN3 (Table I) might be the first evidence of an association between the C5a-C5aR system and human cancer invasion.

Plasma C5a levels are elevated in patients with systemic lupus erythematosus (22) and rheumatoid arthritis (23). The cancer promotion by the Arthus reaction observed in this study suggests that acceleration of cancer progression may occur via elevated C5a level in patients with an autoimmune disease. Recent studies have revealed an association between autoimmunity, including rheumatoid arthritis and thyroiditis, and worse survival in patients with lung, breast, or thyroid cancers (2-4); this likely substantiates a close link of the C5a-C5aR system to cancer aggravation in patients with autoimmune diseases. The cancer cell C5aR-positive rates were different in the primary organs (12); accordingly, in C5aR-positive cancers, the contribution of the C5a-C5aR system to poor prognosis of cancer patients with autoimmune diseases presumably increases. Therefore, blocking this system might be a useful therapeutic approach for cancers, particularly in patients with autoimmune diseases. Improved survival of metastatic renal cell carcinoma patients with genetic deficiency of complement C4 (37), which blocks complement activation by immune complexes and results in absence of C5a generation, further supports the effectiveness of this treatment approach and is consistent with the present results that showed cancer promotion via the C5a-C5aR system. It has been reported that C5a signaling inhibition by an L-aptamer reduced cancer growth and metastasis and prolonged the survival of cancer-burdened mice, with a synergistic effect by a combination with the blockade of programmed cell death 1 (PD-1) (38). Collectively, the C5a-C5aR system may be a promising target for cancer therapy. Furthermore, the association of C5aR expression with poor outcomes in patients with diverse types of cancer (16-21) suggests availability of such a therapy for a broad range of cancers.

\section{Acknowledgements}

The authors would like to thank Ms. Tatsuko Kubo (Department of Molecular Pathology, Kumamoto University, Kumamoto, Japan), and Ms. Honami Miyahara, Ms. Yuri Nakamura, Ms. Mayuko Ueda, Ms. Miharu Ohtsuki, and Ms. Eimi Onizuka (Shokei University, Kumamoto, Japan) for technical assistance. 


\section{Funding}

The present study was supported in part by Japan Society for the Promotion of Science KAKENHI (grant nos. 25460498 and 16K08741) to Takahisa Imamura, (grant no. 17K11879) to Hidenao Ogi and (grant no. 17K11912) to Takuya Tanaka.

\section{Availability of data and materials}

The data of the present study are available from the corresponding author on reasonable request.

\section{Authors' contributions}

MY wrote the initial manuscript. MY, RI, HNi and KT performed animal experiments, and KK performed statistical analysis of data. FS and HK contributed to tissue sample collection. TT and $\mathrm{HO}$ contributed to acquisition and interpretation of animal experiment data and obtained financial support. TI and HNa made substantial contributions to the conception, design and intellectual content of this study. TI performed immunohistochemistry and revised the manuscript. All the authors read and approved the final version of the manuscript.

\section{Ethics approval and consent to participate}

The animal experiments were approved by the Kumamoto University Animal Experiment Committee (A 29-29) and performed according to the criteria of the Committee. Written informed consent for the tissue usage was obtained from the patients, and the use of these tissues was approved by the internal ethics committee (Rinri No. 706).

\section{Patient consent for publication}

Informed consent for publication was obtained from the patients.

\section{Competing interests}

The authors declare that they have no competing interests.

\section{References}

1. Hellewell PG and Rossi AG: Arthus reaction. In: Encyclopedia of immunology. 2nd edition. Delves PJ and Roitt IM, (eds.) Elsevier Academic Press, Amsterdam (Netherlands), pp237-240, 1998.

2. Pak JK, Yang JA, Ahn EY, Chang SH, Song YW, Curtis JR and Lee EB: Survival rate of cancer patients with and without rheumatic disease: A retrospective cohort analysis. BMC Cancer 16: $381,2016$.

3. Criscitiello C, Bangnardi V, Esposito A, Gelao L, Santillo B, Viale G, Rotmensz N, Goldhirsch A and Curigliano G: Impact of autoimmune diseases on outcome of patients with early breast cancer. Oncotarget 7: 51184-51192, 2016.

4. Souza SL, Montalli Da Assumpção LV and Ward LS: Impact of previous thyroid autoimmune diseases on prognosis of patients with well-differentiated thyroid cancer. Thyroid 13: 491-495, 2003.

5. Fernandez HN and Hugli TE: Primary structural analysis of the polypeptide portion of human C5a anaphylatoxin. Polypeptide sequence determination and assignment of the oligosaccharide attachment site in C5a. J Biol Chem 253: 6955-6964, 1978.

6. Guo RF and Ward PA: Role of C5a in inflammatory responses Annu Rev Immunol 23: 821-852, 2005.
7. Markiewski MM and Lambris JD: The role of complement in inflammatory diseases from behind the scenes into the spotlight. Am J Pathol 171: 715-727, 2007.

8. Markiewski MM, DeAngelis RA, Benencia F, Ricklin-Lichtsteiner SK, Koutoulaki A, Gerard C, Coukos G and Lambris JD: Modulation of the antitumor immune response by complement. Nat Immunol 9: 1225-1235, 2008.

9. Corrales L, Ajona D, Rafail S, Lasarte JJ, Riezu-Boj JI, Lambris JD, Rouzaut A, Pajares MJ, Montuenga LM and Pio R: Anaphylatoxin C5a creates a favorable microenvironment for lung cancer progression. J Immunol 189: 4674-4683, 2012.

10. Nozaki M, Raisler BJ, Sakurai E, Sarma JV, Barnum SR, Lambris JD, Chen Y, Zhang K, Ambati BK, Baffi JZ and Ambati J: Drusen complement components C3a and C5a promote choroidal neovascularization. Proc Natl Acad Sci USA 103: 2328-2333, 2006

11. Gerard NP and Gerard C: The chemotactic receptor for human C5a anaphylatoxin. Nature 349: 614-617, 1991.

12. Nitta H, Wada Y, Kawano Y, Murakami Y, Irie A, Taniguchi K, Kikuchi K, Yamada G, Suzuki K, Honda J, et al: Enhancement of human cancer cell motility and invasiveness by anaphylatoxin C5a via aberrantly expressed C5a receptor (CD88). Clin Cancer Res 19: 2004-2013, 2013

13. Niculescu F, Rus HG, Retegan M and Vlaicu R: Persistent complement activation on tumor cells in breast cancer. Am J Pathol 140: 1039-1043, 1992.

14. Bjørge L, Hakulinen J, Vintermyr OK, Jarva H, Jensen TS, Iversen OE and Meri S: Ascitic complement system in ovarian cancer. Br J Cancer 92: 895-905, 2005.

15. Nitta H, Murakami Y, Wada Y, Eto M, Baba H and Imamura T: Cancer cells release anaphylatoxin C5a from C5 by serine protease to enhance invasiveness. Oncol Rep 32: 1715-1719, 2014.

16. Gu J, Ding JY, Lu CL, Lin ZW, Chu YW, Zhao GY, Guo J and Ge D: Overexpression of CD88 predicts poor prognosis in non-small cell lung cancer. Lung Cancer 81: 259-265, 2013.

17. Imamura T, Yamamoto-Ibusuki M, Sueta A, Kubo T, Irie A, Kikuchi K, Kariu T and Iwase H: Influence of the C5a-C5a receptor system on breast cancer progression and patient prognosis. Breast Cancer 23: 876-885, 2016.

18. Wada Y, Maeda Y, Kubo T, Kikuchi K, Eto M and Imamura T: $\mathrm{C} 5 \mathrm{a}$ receptor expression is associated with poor prognosis in urothelial cell carcinoma patients treated with radical cystectomy or nephroureterectomy. Oncol Lett 12: 3995-4000, 2016.

19. Xi W, Liu L, Wang J, Xia Y, Bai Q, Xiong Y, Qu Y, Long Q, Xu J and Guo J: Enrichment of C5a-C5aR axis predicts poor postoperative prognosis of patients with clear cell renal cell carcinoma. Oncotarget 7: 80925-80934, 2016.

20. Kaida T, Nitta H, Kitano Y, Yamamura K, Arima K, Izumi D, Higashi T, Kurashige J, Imai K, Hayashi H, et al: C5a receptor (CD88) promotes motility and invasiveness of gastric cancer by activating RhoA. Oncotarget 7: 84798-84809, 2016.

21. Nitta H, Shimose T, Emi Y, Imamura T, Ohnishi K, Kusumoto T, Yamamoto M, Fukuzawa K, Takahashi I, Higashi H, et al: Expression of the anaphylatoxin C5a receptor in gastric cancer: Implications for vascular invasion and patient outcomes. Med Oncol 33: 118, 2016

22. Sakuma Y, Nagai T, Yoshio T and Hirohata S: Differential activation mechanisms of serum C5a in lupus nephritis and neuropsychiatric systemic lupus erythematosus. Mod Rheumatol 27: 292-297, 2017.

23. Hornum L, Hansen AJ, Tornehave D, Fjording MS, Colmenero P, Wätjen IF, Søe Nielsen NH, Bliddal H and Bartels EM: C5a and $\mathrm{C} 5 \mathrm{aR}$ are elevated in joints of rheumatoid and psoriatic arthritis patients, and C5aR blockade attenuates leukocyte migration to synovial fluid. PLoS One 12: e0189017, 2017.

24. Cream JJ, Bryceson AD and Ryder G: Disappearance of immunoglobulin and complement from the Arthus reaction and its relevance to studies of vasculitis in man. Br J Dermatol 84: 106-109, 1971.

25. Ramos BF, Zhan Y and Jakschik BA: Neutrophil elicitation in the reverse passive Arthus reaction. Complement-dependent and -independent mast cell involvement. J Immunol 152: 1380-1384, 1994.

26. Maeda Y, Kawano Y, Wada Y, Yatsuda J, Motoshima T, Murakami Y, Kikuchi K, Imamura T and Eto M: C5aR is frequently expressed in metastatic renal cell carcinoma and plays a crucial role in cell invasion via the ERK and PI3 kinase pathways. Oncol Rep 33: 1844-1850, 2015. 
27. Shojaei F, Wu X, Malik AK, Zhong C, Baldwin ME, Schanz S, Fuh G, Gerber HP and Ferrara N: Tumor refractoriness to anti-VEGF treatment is mediated by $\mathrm{CD} 11 \mathrm{~b}^{+} \mathrm{Grl}^{+}$myeloid cells. Nat Biotechnol 25: 911-920, 2007.

28. FIGO Committee on Gynecologic Oncology: FIGO staging for carcinoma of the vulva, cervix, and corpus uteri. Int J Gynecol Obstet 125: 97-98, 2014.

29. Koomägi R and Volm M: Expression of Fas (CD95/APO-1) and Fas ligand in lung cancer, its prognostic and predictive relevance. Int J Cancer 84: 239-243, 1999.

30. Rahman MA, Dhar DK, Yamaguchi E, Maruyama S, Sato T, Hayashi H, Ono T, Yamanoi A, Kohno H and Nagasue N: Coexpression of inducible nitric oxide synthase and COX-2 in hepatocellular carcinoma and surrounding liver: Possible involvement of COX-2 in the angiogenesis of hepatitis $\mathrm{C}$ virus-positive case. Clin Cancer Res 7: 1325-1332, 2001.

31. Shvarts O, Janzen N, Lam JS, Leppert JT, Caliliw R, Figlin RA, Belldegrum AS and Zeng G: RENCA/carbonic anhydrase-IX: A murine model of a carbonic anhydrase-IX-expressing renal cell carcinoma. Urology 68: 1132-1138, 2006.

32. Vignesh P, Rawat A, Sharma M and Singh S: Complement in autoimmune diseases. Clin Chim Acta 465: 123-130, 2017.

33. Landgren AM, Landgren O, Gridley G, Dores GM, Linet MS and Morton LM: Autoimmune disease and subsequent risk of developing alimentary tract cancers among 4.5 million US male veterans. Cancer 117: 1163-1171, 2011.
34. Yu KH, Kuo CF, Huang LH, Huang WK and See LC: Cancer risk in patients with inflammatory systemic autoimmune Rheumatic diseases. A nationwide population-based dynamic cohort study in Taiwan. Medicine (Baltimore) 95: e3540, 2016.

35. $\mathrm{Lu} \mathrm{Y}$ and $\mathrm{Hu} \mathrm{XB}$ : C5a stimulates the proliferation of breast cancer cells via Akt-dependent RGC-32 gene activation. Oncol Rep 32: 2817-2823, 2014.

36. Cai K, Wang Y, Wang Z, Wang Y, Zhao X and Bao X: C5a promotes the proliferation of human nasopharyngeal carcinoma cells through PCAF-mediated STAT3 acetylation. Oncol Rep 32: 2260-2266, 2014.

37. Zafar GI, Grimm EA, Wei W, Johnson MM and Ellerhorst JA: Genetic deficiency of complement isoforms C4A or C4B predicts improved survival of metastatic renal cell carcinoma. J Urol 181: 1028-1034, 2009.

38. Ajona D, Ortiz-Espinosa S, Moreno H, Lozano T, Pajares MJ, Agorreta J, Bértolo C, Lasarte JJ, Vicent S, Hoehlig K, et al: A combined PD-1/C5a blockade synergistically protects against cancer growth and metastasis. Cancer Discov 7: 694-703, 2017.

(i) (9) This work is licensed under a Creative Commons Attribution-NonCommercial-NoDerivatives 4.0 International (CC BY-NC-ND 4.0) License. 